\title{
Mesin Carnot Kuantum Berbasis Partikel Dua Tingkat di dalam Kotak Potensial Satu Dimensi
}

\author{
Yohanes Dwi Saputra * dan Agus Purwanto ${ }^{\dagger}$ \\ Laboratorium Fisika Teori dan Filsafat Alam (LaFTiFA), \\ Jurusan Fisika, FMIPA, Institut Teknologi Sepuluh Nopember, \\ Kampus ITS Sukolilo, Surabaya 60111
}

Intisari

Telah dihitung efisiensi mesin Carnot kuantum berbasis partikel dua tingkat di dalam kotak potensial takhingga satu dimensi. Hasilnya hanya bergantung pada rasio volume selama proses adiabatik.

KATA KUNCI: mesin Carnot kuantum, kotak potensial dan efisiensi

\section{PENDAHULUAN}

Mesin panas termodinamika klasik mengkonversi energi panas menjadi kerja mekanik dengan sistem mekanika klasik yang mana gas berekspansi dan menekan piston di dalam silinder. Mesin panas ini memperoleh energinya dari tandon panas temperatur tinggi, beberapa bagian energi yang diambil dikonversi menjadi energi mekanik. Mesin panas tidak efisien secara sempurna yaitu beberapa bagian energi yang diambil dari tandon panas tidak dikonversi ke energi mekanik melainkan ditransfer ke tandon temperatur rendah.

Mesin panas klasik yang bekerja antara tandon temperatur tinggi dan tandon temperatur rendah mencapai efisiensi maksimum jika mesin terbalikkan (reversibel). Sementara tidak mungkin membuat mesin panas yang terbalikkan secara sempurna, tahun 1824 Carnot mengajukan model matematis dari mesin panas ideal yang tidak hanya terbalikkan melainkan juga membentuk siklus. Mesin Carnot terdiri dari silinder berisi gas ideal yang ditempatkan dalam keadaan kontak termal bergantian dengan tandon temperatur tinggi $T_{H}$ dan temperatur rendah $T_{C}[1]$.

Efisiensi dari mesin panas didefinisikan sebagai berikut: Jika sejumlah energi $Q_{H}$ yang diambil dari tandon temperatur tinggi dan sejumlah kerja mekanik W dihasilkan, maka efisiensi $\eta$ dari mesin panas didefinisikan sebagai

$$
\eta=\frac{W}{Q_{H}}
$$

Masalah utama dari mesin panas adalah rendahnya efisiensi. Untuk meningkatkan efisiensi digunakan bahan kuantum sebagai bahan aktif. Efek kuantum diharapkan mampu meningkatkan perbedaan termodinamika antara bahan aktif klasik dan kuantum dari mesin panas.

Konsep mesin panas kuantum pertama kali diperkenalkan oleh Scovil and Schultz-Dubois [2] dan dikembangkan secara lebih intensif empat dasawarsa kemudian. Mesin panas

\footnotetext{
*E-mail:yds@physics.its..ac.id

†E-mail:purwanto@physics.its.ac.id
}

kuantum memanfaatkan efek-efek kuantum seperti tingkat energi diskrit, koherensi kuantum atau kurungan kuantum (quantum confinement) di dalam proses menghasilkan kerja yang berasal dari selisih temperatur.

Di dalam artikel ini, kajian mesin panas difokuskan pada mesin panas menggunakan analogi kuantum dari mesin Carnot klasik. Sistem silinder dan gas digantikan oleh kotak potensial takhingga satu dimensi dan satu partikel di dalam kotak [3], sistem yang telah dikenal baik oleh mahasiswa fisika yang baru mempelajari fisika kuantum.

Di dalam analisa terdahulu [3] diperoleh bahwa efisiensi bergantunga pada rasio antara volume awal sebelum proses berlangsung dan volume akhir terbesar ekspansi menjelang proses termampatkan kembali. Di dalam artikel ini, kajian ulang lebih seksama memberikan bahwa efisisensi bergantung pada rasio volume awal dan akhir proses adiabatik, tidak bergantung pada perbedaan volume proses isotermal.

Artikel ini ditata sebagai berikut. Di Bagian II ditampilkan kembali konsep dasar di dalam termodinamika klasik dan konsep kotak potensial kuantum satu dimensi. Dijelaskan juga analogi gaya dalam proses ekspansi antara konsep klasik dan kuantum. Bagian III menguraikan karakteristik proses isotermal dan adiabatik serta penerapannya dalam siklus Carnot kuantum. Kesimpulan diberikan di Bagian IV.

\section{KOTAK KUANTUM DAN TERMODINAMIKA}

\section{A. Kotak Potensial Takhingga Satu Dimensi}

Sistem kuantum paling sederhana adalah partikel bermassa $m$ berada di dalam kotak potensial takhingga satu dimensi berukuran $L$, lihat referensi [4]. Persamaan Schrodinger di dalam kotak

$$
-\frac{\hbar^{2}}{2 m} \frac{d^{2} \varphi}{d x^{2}}=E \varphi
$$

Syarat batas di kedua ujung kotak yang disebabkan oleh ketakbrhinggaan potensial di kedua ujung kotak adalah $\varphi(0)=$ 
$0=\varphi(L)$ dan normalisasi memberikan fungsi eigen

$$
\varphi_{n}(x)=\sqrt{\frac{2}{L}} \sin \left(\frac{n \pi}{L} x\right)
$$

dan nilai eigen

$$
E_{n}=\frac{\pi^{2} \hbar^{2}}{2 m L^{2}} n^{2}
$$

dengan $n$ adalah bilangan kuantum $n=1,2,3, \cdots$.

Solusi umum persamaan Schrodinger (2) yang menyatakan partikel di dalam kotak dengan energi sembarang $E$ adalah fungsi sembarang $\varphi(x) \rightarrow \psi(x)$ yang memenuhi kondisi $\psi(0)=0=\psi(L)$ selalu dapat dinyatakan sebagai kombinasi linier dari fungsi eigen (3)

$$
\psi(x)=\sum_{n=1}^{\infty} a_{n} \varphi_{n}(x)
$$

dengan koefisien $a_{n}$ memenuhi hubungan

$$
\left|a_{1}\right|^{2}+\left|a_{2}\right|^{2}+\left|a_{3}\right|^{2}+\cdots=\sum_{n=1}^{\infty}\left|a_{n}\right|^{2}=1
$$

Energi $E$ merupakan energi rata-rata

$$
E=\langle E\rangle=\int_{0}^{L} \psi^{*} H \psi d x=\sum_{n=1}^{\infty}\left|a_{n}\right|^{2} E_{n}
$$

\section{B. Termodinamika Sistem Kuantum}

Termodinamika membahas dinamika energi khususnya energi panas dengan parameter-parameter temperatur, tekanan, volume dan massa gas atau bahan dari sistem. Bila temperatur sistem berubah maka secara umum tekanan dan volume sistem juga akan ikut berubah. Keterkatitan antara parameterparameter sistem termodinamika dinyatakan dalam hukum pertama

$$
d Q=d U+d W
$$

Hukum termodinamika ini menyatakan bahwa panas yang diterima sistem $d Q$ akan digunakan untuk menaikkan energi dalam $d U$ dan melakukan kerja $d W$. Perubahan masingmasing akan ditentukan oleh setiap proses terkait, apakah proses adiabatik, isotermal, isobar atau isovolume.

Analogi proses termodinamika untuk partikel di dalam kotak potensial dapat dilakukan seperti berikut. Energi rata-rata partikel terkait dengan temperatur klasik di dalam sistem termodinamika yang mana temperatur sebanding dengan rata-rata energi kinetik partikel.

Di dalam termodinamika klasik, gas sebagai bahan aktif mendorong piston dengan tekanan $P$. Di dalam kotak potensial, lihat FIG.1, dinding kotak $L$ dianggap dapat bergerak dan gerak partikel akan mendorong dinding dengan gaya $F$ yang menyebabkan penurunan energi partikel

$$
F=-\frac{d E}{d L}
$$

Untuk partikel dengan energi (10) maka gaya partikel pada dinding diberikan oleh

$$
F=\sum_{n=1}^{\infty}\left(n^{2}\left|a_{n}\right|^{2}\right) \frac{\pi^{2} \hbar^{2}}{m L^{3}}
$$

Secara umum koefisien $a_{n}$ bergantung pada $L$.

Jika partikel mendorong dinding kotak dari $L_{1}$ dan bergeser sampai $L_{2}$ maka partikel melakukan kerja

$$
W=\int_{L_{1}}^{L_{2}} F d L
$$

yang secara umum dapat diperoleh dari panas yang masuk dari luar dan perubahan energi dalam.

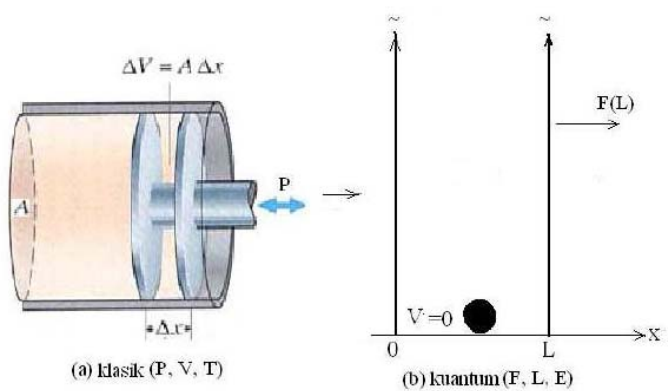

Gambar 1: Analogi Piston dan Kotak Potensial

\section{MESIN CARNOT KUANTUM}

\section{A. Proses Adiabatik}

Di dalam proses adiabatik sistem diisolasi secara termal dengan dinding adiabatik sehingga panas tidak dapat masuk atau keluar sistem, $d Q=0$. Di dalam proses ini piston bergerak tetapi sistem tetap dalam keadaan setimbang setiap saat. Ketika piston bergerak, gas di dalam silinder melakukan kerja. Dengan demikian, beberapa energi gas dikonversi ke dalam energi mekanik. Kerja terjadi karena penurunan energi dalam gas.

$$
-d U=d W
$$

Karena sistem dalam keadaan setimbang dan tanpa panas masuk atau keluar maka keadaan sistem

$$
\psi(x)=\sum_{n} a_{n} \varphi_{n}(x)
$$

tetap. Tepatnya, selama proses adiabatik koefisien $a_{n}$ tetap.

\section{B. Proses Isotermal}

Di dalam proses isotermal sistem mengalami kontak termal dengan tandon panas dan panas dapat masuk sistem. Akibatnya, selama proses ini partikel di dalam tandon dapat mengalami transisi keadaan sehingga secara umum koefisien $a_{n}$ 
dari kedaan (13) mengalami perubahan,

Meskipun keadaan mengalami transisi, selama proses ini berlangsung kesetimbangan tetap dipertahankan dan temperatur tidak mengalami perubahan. Untuk gas ideal yang hanya bergantung pada temperatur maka energi dalam gas, dengan demikian juga tidak mengalami perubahan, $d U=0$. Ini berarti bahwa panas yang diserap gas digunakan untuk melakukam usaha

$$
d Q=d W
$$

\section{Siklus Carnot Kuantum}

Sekarang kita tinjau kasus spesifik yaitu siklus carnot untuk partikel di dalam kotak potensial. Siklus Carnot terdiri dari empat proses yang masing-masing terbalikkan. Pertama, partikel di dalam kotak mengalami ekspansi isotermal pada temperatur $T_{H}$ sambil kontak dengan tandon panas. Kedua, partikel mendorong dinding secara adiabatik yakni dalam keadaan terisolasi termal sampai temperatur jatuh menjadi $T_{C}$. Ketiga, partikel di dalam kotak ditekan secara isotermal dalam keadaan kontak dengan tandon temperatur rendah. Keempat, partikel ditekan kembali tetapi secara adiabatik sampai mencapai temperatur $T_{H}$ seperti diberikan oleh FIG.2.

Di dalam artikel ini, kita membatasi pada sistem partikel

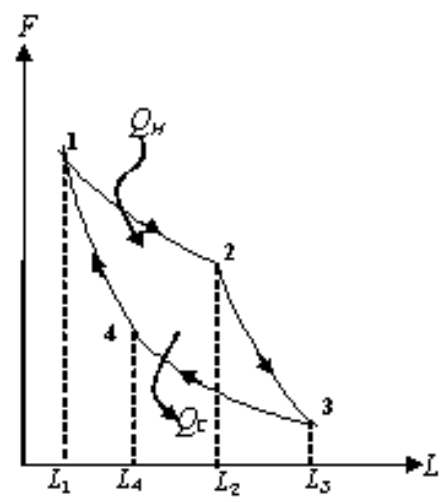

Gambar 2: Siklus Mesin Carnot

hanya dengan dua keadaan yaitu keadaan dasar $\varphi_{1}$ dengan energi eigen $E_{1}$ dan keadaan tereksitasi pertama $\varphi_{2}$ dengan energi eigen $E_{2}$.

Kita berangkat dari kondisi awal kotak potensial selebar $L_{1}$ dan partikel dalam keadaan dasar dengan energi $E_{1}$

$$
E_{1}=\frac{\pi^{2} \hbar^{2}}{2 m L_{1}^{2}}
$$

\section{Proses Isotermal 12}

Partikel mendorong dinding secara isotermal yang berarti bahwa partikel mendorong dinding sambil kotak beriteraksi dengan tandon. Partikel mengalami transisi atau tereksitasi sehingga keadaan aktual selama proses ini adalah

$$
\psi(x)=a_{1}(L) \sqrt{\frac{2}{L}} \sin \frac{\pi x}{L}+a_{2}(L) \sqrt{\frac{2}{L}} \sin \frac{2 \pi x}{L}
$$

dengan koefisien $a_{1}$ dan $a_{2}$ memenuhi

$$
\left|a_{1}\right|^{2}+\left|a_{2}\right|^{2}=1
$$

Energi partikel selama nebdorong dinding sumur

$$
\begin{aligned}
E(L) & =\left|a_{1}\right|^{2} E_{1}+\left|a_{2}\right|^{2} E_{2} \\
& =\left(4-3\left|a_{1}\right|^{2}\right) \frac{\pi^{2} \hbar^{2}}{2 m L^{2}}
\end{aligned}
$$

Energi ini sama dengan energi $E_{1}(15)$ yaitu energi ketika sistem dalam kondisi awal. Kaitan kedua energi ini memberi hubungan

$$
L^{2}=\left(4-3\left|a_{1}\right|^{2}\right) L_{1}^{2}
$$

Gaya yang dilakukan partikel untuk mendorong dinding kotak $L$,

$$
F_{12}(L)=\frac{\pi^{2} \hbar^{2}}{m L_{1}^{2} L}
$$

Partikel terus melakukan usaha dengan mendorong dinding, jarak terjauh yang dapat dicapai dinding adalah

$$
L=L_{2}=2 L_{1}
$$

Ketika dinding kotak mencapai jarak maksimum $2 L_{1}$ ini, dari pers.(19) tampak bahwa $a_{1}=0$ yang berarti keadaan menjadi murni tereksitasi $\psi=\varphi_{2}$

$$
\psi(x)=\sqrt{\frac{2}{L_{2}}} \sin \frac{2 \pi x}{L_{2}}
$$

dengan energi $E=E_{1}=E_{2}$,

$$
E_{2}=\frac{4 \pi^{2} \hbar^{2}}{2 m L_{2}^{2}}
$$

\section{Proses Adiabatik 23}

Setelah mencapai keadaan dua, $L_{2}$, keadaan akhir dari proses isotermal, sistem melanjutkan proses ekspansi dalam situasi terisolasi yaitu proses adiabatik. Selama proses ini tidak terdapat panas masuk kotak, partikel tetap dalam keadaan $\varphi_{2}$ yaitu $a_{2}$ tetap dan kerja mendorong dinding diperoleh dari penurunan energi dalam

$$
E=\frac{4 \pi^{2} \hbar^{2}}{2 m L^{2}}
$$

Gaya yang dilakukan untuk mendorong dinding di $L$ adalah

$$
F_{23}=\frac{4 \pi^{2} \hbar^{2}}{m L^{3}}
$$


Ekspansi adiabatik dari $L_{2}$ berakhir di $L_{3}$ misalkan

$$
L_{3}=\alpha L_{2}
$$

dengan faktor $\alpha>1$. Fungsi keadaan partikel di akhir ekspansi adiabatik adalah

$$
\psi(x)=\varphi_{2}(x)=\sqrt{\frac{2}{L_{3}}} \sin \frac{2 \pi x}{L_{3}}
$$

dengan energi

$$
E_{3}=\frac{4 \pi^{2} \hbar^{2}}{2 m L_{3}^{2}}=E_{2} / \alpha^{2}
$$

\section{Proses Isotermal 34}

Proses selanjutnya, sumur termampatkan sambil kontak termal sehingga partikel mengalami transisi dan mepunyai keadaan

$$
\psi(x)=a_{1} \varphi_{1}(x)+a_{2} \varphi_{2}(x)
$$

dengan temperatur dipertahankan. Energi dalam (18) selama proses pemampatan isotermal ini sama dengan energi $E_{3}(28)$. Hubungan antar lebar sumur dan koefisien transisi $a_{1}$ berbentuk

$$
L^{2}=\frac{4-3\left|a_{1}\right|^{2}}{4} L_{3}^{2}
$$

Gaya partikel menahan dinding

$$
F_{34}(L)=\frac{4 \pi^{2} \hbar^{2}}{m L_{3}^{2} L}
$$

Pers.(30) membatasi pemampatan maksimum yaitu ketika keadaan menjadi murni keadaan dasar $a_{2}=0, a_{1}=1$ yang terjadi ketika

$$
L_{4}=\frac{L_{3}}{2}
$$

Pada saat sumur selebar $L_{4}$ fungsi eigen partikel

$$
\psi(x)=\varphi_{1}(x)=\sqrt{\frac{2}{L_{4}}} \sin \frac{\pi x}{L_{4}}
$$

dengan energi eigen $E_{4}=E_{3}$.

\section{Proses Adiabatik 41}

Selanjutnya, gas dengan keadaan dasar termampatkan secara adiabatik sampai sumur berukuran $L_{1}$. Gaya partikel menahan dinding antara $L_{4}$ dan $L_{1}$ adalah

$$
F_{41}=\frac{\pi^{2} \hbar^{2}}{m L^{3}}
$$

\section{Kerja dan Efisiensi Mesin}

Dari siklus proses kuantum di depan kita dapat menghitung usaha total yang dilakukan mesin. Usaha yang dilakukan se- lama empat proses kuantum tersebut adalah

$$
\begin{aligned}
W= & \oint F d L \\
= & \int_{L_{1}}^{L_{2}} F_{12} d L+\int_{L_{2}}^{L_{3}} F_{23} d L \\
& +\int_{L_{3}}^{L_{4}} F_{34} d L+\int_{L_{4}}^{L_{1}} F_{41} d L
\end{aligned}
$$

Lebar sumur akhir setiap proses (21), (26) dan (32) terkait dengan lebar sumur awal

$$
L_{2}=2 L_{1}, L_{3}=2 \alpha L_{1}, L_{4}=\alpha L_{1}
$$

dengan $\alpha$ adalah faktor yang menghubungkan lebar sumur awal dan lebar akhir proses adiabatik (26). Selanjutnya, subtitusi gaya-gaya (20), (25), (31) dan (34) serta lebar sumur (36) diperoleh

$$
W=\frac{\pi^{2} \hbar^{2}}{m L_{1}^{2}} \ln 2\left(1-\frac{1}{\alpha^{2}}\right)
$$

Sedangkan panas yang diserap mesin adalah

$$
Q_{H}=\int_{L_{1}}^{L_{2}} F_{12} d L=\frac{\pi^{2} \hbar^{2}}{m L_{1}^{2}} \ln 2
$$

Dengan demikian, dari kerja (39) dan panas yang diserap (38) diperoleh efisiensi mesin

$$
\eta=1-\frac{1}{\alpha^{2}}
$$

yang hanya bergantung pada rasio $\alpha=L_{3} / L_{2}$.

\section{KESIMPULAN}

Kita telah evaluasi sistem termodinamika kuantum paling sederhana yakni kotak potensial takberhingga satu dimensi dengan satu partikel. Sistem mengembang dengan proses siklus Carnot dan efisiensi hanya bergantung pada rasio lebar sumur awal dan akhir proses adiabatik. Jika $\alpha=2$ yakni ketika ukuran kotak akhir kedua proses isotermal sama maka efisiensi mesih adalah 75 persen.

Meningat tingkat keadaan sistem kuantum umumnya tidak hanya dua maka menarik untuk mengkaji proses bagi sistem dengan keadaan berhingga lebih dari dua dan keadaan berhingga. Kajian hal terakhir ini sedang dalam progres.

\section{Ucapan Terima Kasih}

AP sampaikan terimakasih kepada Dr Darminto yang telah memberi kesempatan untuk mempresentasikan dan mendiskusikan masalah ini di dalam Forum Seminar Seninan Jurusan Fisika ITS yang telah berlangsung sejak 2003. 
[1] F.W. Sears and G.L. Salinger, Thermodynamics, Kinetic Theory, and Statistical Thermodynamics (Addison Wesley, Massachusetts, 1975).

[2] H. Scovil and E. Schulz-Dubois, Phys. Rev. Lett. 2 262(1959).
[3] C.M. Bender, D. C. Brody, and B. K. Meister, J. Phys. A 33 4427(2000).

[4] A. Purwanto, Fisika Kuantum (GavaMedia, Yogyakarta, 2006) 